\title{
EMPLOYEES CHARACTERISTICS IN KNOWledge Transfer and PerformanCE
}

\author{
Saide $^{1}$, Hsiao-Lan $\mathrm{Wei}^{2}$, Apol Pribadi Subriadi ${ }^{3}, \mathrm{Okfalisa}^{4}$, Nurul Aini ${ }^{5}$, \\ and Nesdi Evrilyan Rozanda ${ }^{6}$ \\ ${ }^{1}$ Department of Information Management, National Taiwan University of \\ Science and Technology (NTUST), Taiwan. Department of Information System, \\ Institute Technology of Sepuluh Nopember (ITS), Surabaya, Indonesia. \\ saidefc@gmail.com \\ ${ }^{2}$ Department of Information Management, National Taiwan University of \\ Science and Technology (NTUST), Taiwan. \\ hlwei@cs.ntust.edu.tw \\ ${ }^{3}$ Department of Information System, Institute Technology of Sepuluh Nopember \\ (ITS), Surabaya, Indonesia \\ apoleis.its.ac.id \\ ${ }^{4}$ Department of Informatics Engineering, State Islamic University of Sultan \\ Syarif Kasim Riau (UIN Suska Riau), Riau, Indonesia. \\ okfalisa@gmail.com \\ ${ }^{5}$ Department of Information System, Diponegoro University, Semarang, \\ Indonesia. \\ Nuruldotaini@gmail.com \\ ${ }^{6}$ Department of Information System, State Islamic University of Sultan Syarif \\ Kasim Riau (UIN Suska Riau), Riau, Indonesia. \\ nesdiev@yahoo.com
}

\begin{abstract}
While most studies are concerned with the industry, but for non-profit organizations has not received much attention. Various have highlighted knowledge transfer (KT) for creates value, however an obstacle from the perspective among employees still exists. The main problem is still difficult because employees will not share their knowledge. This study investigated factors and develop that influence KT among employees of non-profit organizations in Indonesia. The survey 364 respondents were used, 325 were returned, and 39 were not returned. Likert and smart PLS to confirm construct. This paper conclude factors that helping others, trust, soft reward, and personality of employees motivation are factors which influencing the KT behaviour. Finally, the findings were discussed.
\end{abstract}

\section{KEYWORDS}

Knowledge Management (KM), Knowledge Transfer (KT), Knowledge Performance, Smart PLS, Employees Characteristics, Indonesia

\section{INTRODUCTION}

Strategic plan each companies may impacts to progress and setbacks performance of the company. This is determined by seriously support from peoples at all level in company. Therefore, the maximizing transfer all resources together (employees and knowledge) that 
possessed must be closely connected with the presence from employees contribution in knowledge practice.

Based on the data from the Delphi Research Group that nearly 50\% of $100 \%$ of organizational knowledge stored in the mind of their employees [1].That is to say, in the future the company needs to seriously attention for how to capture existing assets in the minds of their employees to be shared other employees and to achieve business objectives.

According to [2], knowledge transfer is a process where individual exchange his or her knowledge and ideas through discussions to create new knowledge or ideas. For individual employees, knowledge transfer is talking to colleagues to help them get something done better, more quickly, or more efficiently. Knowledge transfer can helps employees to new understanding their jobs and bring personal recognition within the department. Knowledge transfer include employee willingness to communicate actively with colleagues (i.e. donate knowledge), and actively consult with colleagues to learn from them (i.e. collect knowledge)

However, this is not always easy, because it is still embedded paradigm that tangible assets are always given more attention, while the capacity and scientific (intangible assets) actors rarely get more servings. In fact, if the long-term of mind-set puts forward that the challenge for productivity of all resources can be productively together.

A critical problem regarding the knowledge base in an organization is making employees willing to transfer knowledge from an employee to other employees or to the organization. This problem arises from the employee himself or the organization climate. An employee may be anxious that he will lose his power or value by transfer his knowledge.

Individuals do not always willing to share their knowledge and they may not be willing to share as much as the organization would like them to. It is important to understand when people are willing to share their knowledge and how an organization can facilitate this type of behaviour from both research and practical standpoint.

This is important because it is still crucial to accurately explain the knowledge transfer behaviour of individual professional groups [3]. This idea is also in line with suggestions from previous studied stating that findings from current studies need to be expanded team and organizational level knowledge is influenced by the extent to which knowledge transfer occurs between employees [4]-[7].

Therefore, while reciprocation arguably has attracted most attention, the author believe there are other reasons that deserve further research attention. Most studies in the literature, relating to all aspects of KM, are concerned with the manufacturing industry, and non-profit in particular has not received much attention, especially in Indonesia. This study differs essentially from prior studies by examining existing factors of knowledge transfer in the context where the employees come from different culture in Indonesia's organizations.

\section{LITERATURE REVIEW}

Nowadays, the ability of individuals in organization to share their knowledge within them is identifying as one of the critical contributing factors for organizational competitiveness. Due to this reason, there is a need to study the factors that influence individual knowledge transfer behaviour in organizations.

Knowledge management (KM) is critical to the operation of modern organizations and has attracted much attention by the business world since the introduction of the concept by [5], [8]. It 
can help businesses retain their valuable intangible assets that are keeping in the mind of their employees. Particularly, effective knowledge transfer among units of an organization has been one of the most important issues of KM.

According to [9], there are two benefits organization gained if the members in organization shared their knowledge. Firstly, valuable knowledge can be disseminating effectively and efficiently within the organization through the process of knowledge transfer. Secondly, the ability of individual knowledge to recognize the value of knowledge, assimilate it, and apply it in the commercial end, can be increase by knowledge transfer among individuals of an organization. Knowledge transfer offers an organization the potential for increased productivity as well as retention of intellectual capital, even after employees leave the organization, which is necessary for business that creates value added [10].

Previous researchers tried to found what the reason why the employee didn't to share them knowledge to other and have noted that firms can successfully promote a knowledge transfer culture not only by directly incorporating knowledge in their business strategy, but also by changing employee attitudes and behaviours to promote willing and consistent knowledge transfer, like mentioned by [11]-[13]. This is a crucial process for an organization to become successful. [14]-[16] found that anticipated extrinsic rewards had a negative effect on attitudes toward knowledge transfer. Several studies found no relationship between extrinsic motivation and knowledge transfer intentions or attitudes toward knowledge transfer [10], [17].

It is important to recognize that employees may decide to share (or not share) knowledge for various reasons. For example, as [18] reviewed earlier, research has shown that individuals may share knowledge because they enjoy helping others as a result of reciprocation. It is a problem to encourage the employees to share their knowledge because the knowledge is with them and is a sign of power to them [19]. Achieving effective knowledge transfer practices thus depends on individuals' willingness to put significant effort into the associated social processes [20].

\section{KNOWLEDGE TRANSFER}

$\mathrm{KM}$ is the process through which organizations generate value from their intellectual and knowledge based assets. Defined in this manner, it becomes apparent that KM is concerned with the process of identifying, acquiring, distributing and maintaining knowledge that is essential to the organization.

The presence of KM concept began to attract attention as a device capable of supporting the company in maximizing the knowledge and information at all levels of management to help improve the performance of the company [21], [22]. An increasing performance is supported by KM practice and find successful implementation requires integration of four pillars, namely leadership, learning, organizational structure, and technology.

Knowledge creation phase includes the emergence of knowledge from the origin to the development, later stages of development, such as documentation of knowledge, recorder of knowledge, transfer of knowledge, and distribution of knowledge. There are two main aspects of $\mathrm{KM}$, namely, information management and people management [23]. Viewed from this perspective, KM is about information, on one hand, and people, on the other.

Organizations must also consider how to transfer expertise and knowledge from experts who have it to novices who need to [24]. The presence of KM concept began as a device capable of supporting about how the company should maximize the knowledge and information asset at all levels management to help improve performance of the company. 
Knowledge transfer challenges were caused by the fact that knowledge has become a routine process, but the employees are not fully aware of the separate steps taken in the process of explicitly expressing knowledge [22]. The fundamental reason why Japanese companies are successful, because of their skills and experience was created of organizational knowledge [5]. Knowledge creation is achieved through acquiring of synergistic relationship between tacit and explicit knowledge.

The process of knowledge integration often encounters barriers i.e. tacit and knowledge that are embedded in routines and standalone [25]. Tacit knowledge that exists in system and the organization made the implementation knowledge integration to be slow and difficult [13] [5].

There is ongoing debate on what is the most important enabler for KM. A number of management analysts contend that technology is the most important. Others consider people to be the most important in knowledge management and argue that $\mathrm{KM}$ initiatives that focus mainly on technology can and do often fail. Both are, of course, important to the success of any KM systems. But the success of a KM systems depends on many factors, and among the most important is the efficient management of people and culture within the organization.

Ways to do this include encouraging communication, offering opportunities to learn, and promoting the transfer of appropriate knowledge artefact (KM is an attempt to increase the useful knowledge in the organization, among nurture a culture of communication between personnel, provide opportunities for learning, and promoting each other to share the knowledge).

\section{FRAMEWORK}

The research framework (see Fig. 1) is formulated based on selected related research as important factors that influence knowledge transfer and performance. These factors of knowledge transfer behaviour in the research framework were derived from existing constructs in the knowledge transfer and knowledge performance domain [10], [26]-[31].

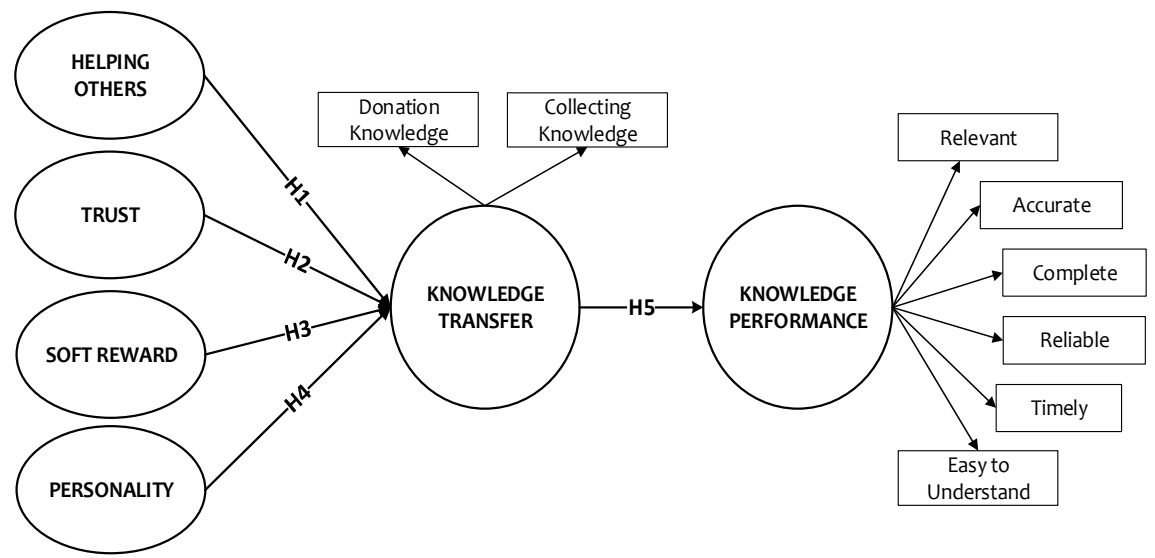

Figure 1. Research Framework

Six variables were selected to form the six hypotheses highlighted (H1, H2, H3, H4 and H5) in the research framework and empirically tested. The following discussion is presented to support our hypotheses.

\subsection{Helping Others to Knowledge Transfer}

Knowledge employees may be motivated by relative helping others owing to their desire to help others [8] [32]. Helping others as including discretionary behaviours that help specific others with organizationally relevant tasks or problems Organ (1998) as cited in [33]. Previous research 
shows that employees are intrinsically motivated to contribute knowledge because engaging in intellectual pursuits and solving problems is challenging or pleasurable, and because they enjoy helping others [34].

\subsection{Trust to Knowledge Transfer}

Study conducted by [18] examined the impact of trust as a contextual factor and postulated that the degree of trust has an impact on collaborative efficiency in the organization. Many previous studies [35]-[39] have reported that a high level of trust facilitates knowledge transfer. Thus it concludes that high level of interpersonal trust correlate with high levels or willingness to knowledge transfer Kalantzis \& Cope (2003) as cited in [2]. Many people are willing to share their knowledge with others if they feel that the person is honest and can be trusted [40].

\subsection{Soft Reward to Knowledge Transfer}

Soft rewards are defined as individuals expectations of achieving implicit outcomes (e.g., personal reputation and relationships with significant others) in return for performing knowledge transfer behaviour [18], [41], [42]. In addition, soft rewards may make individuals feel implicitly controlled or pressured to perform the behaviour due to the implicit consequences related to the behaviour, and are thus forms of interjected regulations/moderately controlled motivations [43], [44]. The following hypotheses are thus proposed.

\subsection{Personality to Knowledge Transfer}

The results of multiple regression analysis indicate that personality is the most significant predictor of knowledge performance followed by trust and awareness. This is evident when Awad \& Ghaziri (2004) as cited in [28] suggest factors like personality and attitude; also suggests helpingothers in helping others and self-efficacy [33] and identifies motivations, trust and care that enable knowledge transfer [45].

\subsection{Knowledge Transfer to Knowledge Performance}

These two distinct processes are active processes in the sense that one is either engaged in active communication with others for the purpose of transferring knowledge, or consulting others in order to gain some access to their intellectual capital [46]. Knowledge donating aims to see individual knowledge become group and organizational knowledge over time, which in turn improves the stock of knowledge available to the firm [47]. However, previous research is still limitation discussed about collecting and receiving of knowledge that influence to knowledge transfer performance. According to [30] a system can be evaluated in terms of information quality. These items are known as main independent factors of the Delone and Maclean IS (information systems) success model. Then [48] mentioned that knowledge could be added to the information quality of the model as information or knowledge performance for achieving the KM success model. The performance of knowledge transfer was examined by the scale adapted from [29], [30].

\section{RESEARCH METHOD}

The data was collected by questionnaires, the data of this study also was taken from the non-profit organizations in Indonesia. 


\subsection{Sample and Data}

We estimated total of respondents is about 364 respondents from 6 institutions that are willing to joint this research. The details are 4 universities and 2 schools in 3 district of Riau Province in

Indonesia. For respondents in non-profit organization that total questionnaires returned is 325 of 364 questionnaires that we provided, there are 39 questionnaires were not returned. In this study, we used a structured questionnaire consisting of three parts. The first part is the briefly introduction about the important of this research. The second part is the demographic information about the participants which had seven demographic items including participant current position, age, how long participants have been work for company, education level of respondents, gender, name and email. The third part of the questionnaire measures based on the constructs in the research model, in conjunction with thirty-three main questionnaire items and also the last part of the questionnaire is the comment section by respondents for this study.

\subsection{Measures}

PLS and SPSS were used because its premises are less limiting and the sample size of data was relatively small [49]. These items were scored using Likert scale with 5 five-points, which 1 corresponds to "strongly disagree" and 5 to "strongly agree. We assess knowledge transfer behaviour using 8 items adapted from [31], [50]. For motivation and individual characteristics measures 15 items were adapted and we divided into four factors groups that helping others with 4 items, 4 items for trust, reward with 4 items and 3 items for personality adapted based on the study [10], [28], [51], [52]. For knowledge transfer performance we assess using 6 items adapted from [29], [30], [53]

\section{RESULTS}

To examine our proposed research model at both individual and organizational levels, the PLS technique was used for the data analysis. SmartPLS 3.2 was adopted for measurement validation and for testing the structural model based on the data collected from the 325 survey respondents in 6 non-profit organizations. Confirmatory factor analysis was performed to examine the validity and reliability of the constructs. In addition, a bootstrapping procedure was conducted for the significant tests of the research hypotheses.

Based on table 3 that show for male and female were $50.8 \%$ and $48.8 \%$, is missing $1.2 \%$. The questionnaire survey about job title of respondents were dean / vice dean $(1.5 \%)$, chairman of department $(2.8 \%)$, head of division $(7.7 \%)$, staff $(49.9 \%)$, secretary $(0.9 \%)$ and staff is the biggest number (34.5\%). The biggest of responses come from lecturer / teacher is $52.6 \%$.

To assess confidence in their answers, respondents were also asked to indicate how long they had worked in their firms. Based on the data SPSS result Table 1, we know that $26.5 \%$ of the respondents had worked $1-3$ years, $16.3 \%$ of the respondents had worked $4-6$ years, $27.4 \%$ of the respondents had worked $7-9$ years, $9.5 \%$ of the respondents had worked $10-12 \%$ years, and $18.8 \%$ of the respondents had worked for more than 13 years.

For education level, there is any the respondents of education in S3 (Doctoral) level is 2 respondents or $0.6 \%$ and for $\mathrm{S} 2$ (Master) 167 respondents or $51.4 \%, 20.9 \%$ of the respondents are S1 (Bachelor) level, 13.8\% of the respondents are D3 (Diploma III) level, 11.1\% of the respondents are Senior High School level, and for elementary school level only $0.6 \%$ of the respondents. 
Table 1. Profile of Respondent $(\mathrm{N}=325)$

\begin{tabular}{llcc}
\hline \multirow{2}{*}{ Sample Characteristics } & Frequency & \% \\
\hline \multirow{5}{*}{ Job Title } & Dean / Vice Dean & 5 & 1.5 \\
& Chairman of Department & 9 & 2.8 \\
& Head of Division & 25 & 7.7 \\
& Lecturer / Teacher & 171 & 52.6 \\
& Secretary & 3 & 0.9 \\
& Staff & 112 & 34.5 \\
\hline \multirow{5}{*}{ Working Year } & 1-3 years & 86 & 26.5 \\
& 4-6 years & 53 & 16.3 \\
& 7-9 years & 89 & 27.4 \\
& 10-12 years & 31 & 9.5 \\
& More than 13 years & 61 & 18.8 \\
& Missing & 5 & 1.5 \\
\hline \multirow{5}{*}{ Education Level } & 2 & 0.6 \\
& S3 & 167 & 51.4 \\
& S2 & 68 & 20.9 \\
& S1 & 45 & 13.8 \\
& Senior High School & 36 & 11.1 \\
& Elementary School & 2 & 0.6 \\
& Missing & 5 & 1.5 \\
\hline \multirow{5}{*}{ Gender } & Male & 165 & 50.8 \\
& Female & 156 & 48.8 \\
& Missing & 4 & 1.2 \\
\hline \multirow{5}{*}{} & & &
\end{tabular}

\subsection{The Measurement Model}

The measurement model was first assessed by CFA. The measurement model was further assessed for construct reliability and validity. Computing composite reliability assessed construct reliability. The composite reliability for each construct of this study is presented in Table 2 . The composite reliability values was used to examine reliability shown in table 3 , which all of the constructs composite reliability was exceed recommended cutoff of 0.7 that indicating a commonly acceptable level for confirmatory research [54].

\subsubsection{Convergent Validity:}

Convergent validity was evaluated for measurement scales using three criteria suggested by [55][59]. All indicator factor loading should be significant and exceed 0.6, composite reliability should exceed 0.7, and average variance extracted (AVE) from each construct should exceed 0.5 [55]-[59].

Table 2. Factors loadings and reliability

\begin{tabular}{lcccccc}
\hline Constructs & Items & Loadings & Status & CA & AVE & CR \\
\hline Helping & HO 1 & 0.85 & Valid & & & \\
Others & HO 2 & 0.91 & Valid & & & \\
& HO 3 & 0.90 & Valid & & 0.70 & 0.90 \\
& HO 4 & 0.68 & Invalid & & & \\
Trust & Trs 1 & 0.74 & Valid & & & \\
& Trs 2 & 0.78 & Valid & 0.79 & 0.62 & 0.86 \\
& Trs 3 & 0.86 & Valid & & & \\
& Trs 4 & 0.75 & Valid & & &
\end{tabular}




\begin{tabular}{lcccccc}
\hline Constructs & Items & Loadings & Status & CA & AVE & CR \\
\hline Soft Reward & Srd 1 & 0.85 & Valid & & & \\
& Srd 2 & 0.92 & Valid & & & \\
& Srd 3 & 0.90 & Valid & 0.92 & 0.80 & 0.94 \\
& Srd 4 & 0.90 & Valid & & & \\
Personality & Per 1 & 0.84 & Valid & & & \\
& Per 2 & 0.80 & Valid & 0.75 & 0.66 & 0.85 \\
Knowledge & Per 3 & 0.80 & Valid & & & \\
Transfer & Col 1 & 0.77 & Valid & & & \\
& Col 2 & 0.80 & Valid & & & \\
& Col 3 & 0.73 & Valid & & & \\
& Col 4 & 0.65 & Invalid & 0.84 & 0.51 & 0.88 \\
& Don 1 & 0.77 & Valid & & & \\
& Don 2 & 0.70 & Valid & & & \\
Knowledge & Don 3 & 0.64 & Invalid & & & \\
Performance & Don 4 & 0.56 & Invalid & & & \\
& KP 1 & 0.68 & Valid & & & \\
& KP 2 & 0.80 & Valid & & & \\
& KP 3 & 0.83 & Valid & & \\
& KP 4 & 0.87 & Valid & 0.88 & 0.62 & 0.91 \\
& KP 5 & 0.82 & Valid & & & \\
& KP 6 & 0.71 & Valid & & & \\
\hline
\end{tabular}

Note: CA (Cronbach Alpha), AVE (Average Variance Extracted), CR (Composite Reliability)

The data collected were subjected to convergent and discriminant validity analysis before the final analysis was conducted. Factor loadings, composite reliability and average variance extracted were used to assess convergence validity. The loadings for all items exceeded the recommended value of 0.7 except items for Don 3 and 4 (knowledge transfer). Composite reliability values (see Table 2), which showed the degree to which the items indicated the latent construct, ranged from 0.70 (KT) to 0.94 (soft reward), which exceeded the recommended value of 0.7 [55]-[59]. The average variance extracted (AVE) was in the range of 0.51, which exceeded the recommended value of 0.5 and 0.7 [55]-[59].

\subsubsection{Discriminant Validity}

Discriminant validity measure by cross loading [60]. Discriminant validity can be examined by comparing the squared correlations between constructs and variance extracted from a construct. Table 3 indicating the measure has adequately discriminant validity.

Table 3. Correlation matrix (fornell-larcker) and discriminant validity

\begin{tabular}{lllllll}
\hline \multicolumn{1}{c}{ Constructs } & AL & KSB & KSQ & PE & RE & TR \\
\hline HO & $\mathbf{0 . 8 4}$ & & & & & \\
KT & 0.46 & $\mathbf{0 . 7 1}$ & & & & \\
KP & 0.30 & 0.61 & $\mathbf{0 . 7 9}$ & & & \\
PE & 0.34 & 0.52 & 0.51 & $\mathbf{0 . 8 1}$ & & \\
SR & 0.44 & 0.48 & 0.37 & 0.44 & $\mathbf{0 . 8 9}$ & \\
TR & 0.34 & 0.43 & 0.36 & 0.26 & 0.36 & $\mathbf{0 . 7 8}$ \\
\hline
\end{tabular}

Note: $\mathrm{HO}$ (Helping Others), KS (Knowledge Transfer), KP (Knowledge Performance), PE (Personality), SR (Soft Reward), TR (Trust). 


\subsection{The Model and Hypotheses Results}

The results of the structural model analysis are displayed in Figure 2. The structural model links the constructs to one another. Analysis of the structural model is the analysis of patterns of relationships between variables is an analysis of the hypotheses of the study. Research hypothesis is acceptable if a connection variable correlated positively and significantly based on the test results of the t-test and path coefficients.

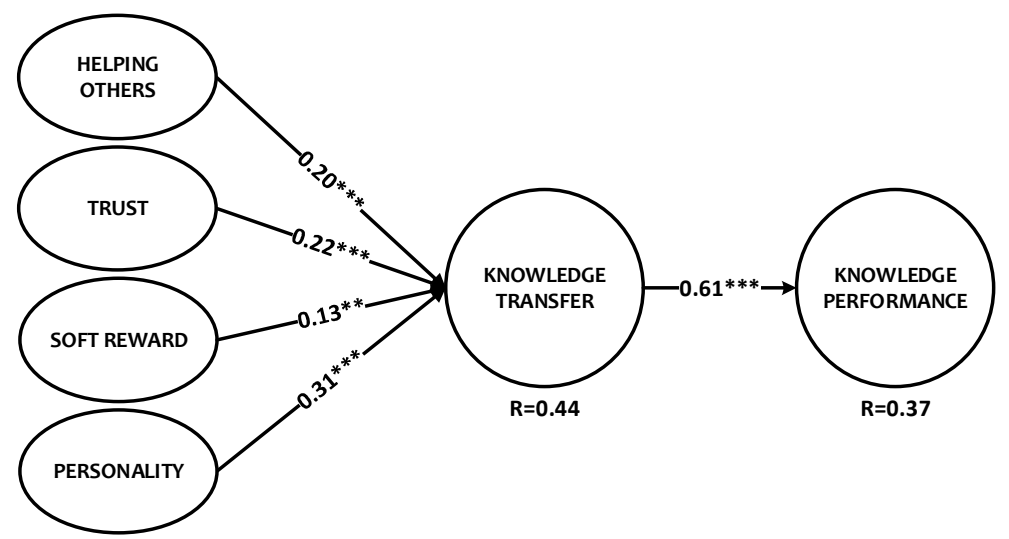

Figure 2. Results of structural model.

To identify the relationship between individual factors and knowledge performance, correlation analysis was conducted. Correlation analysis indicates the strength and direction of relationship between the independent and dependent variables under studied. The result of correlation analysis shows that all the variables are significantly correlated with knowledge transfer behaviour and knowledge performance. Based on Table 4 shows that the relationship between variables is positive or positively correlated and significant effect (t-statistic has a value greater than $1.96 *$ for p-value $<0.05,2.59^{* *}$ for $\mathrm{p}$-value $<0.01$, and $3.32^{* * *}$ for $\mathrm{p}$-value $<0.001$ of 325 respondents).

Table 4. Hypothesis tests based on PLS-SEM based model

\begin{tabular}{|c|c|c|c|c|c|}
\hline Hypothesis & Hypothesis Path & Coefficients & T-Values & P-Values & $\begin{array}{c}\text { Accept / } \\
\text { Reject }\end{array}$ \\
\hline H1 & $\begin{array}{l}\text { Helping Others } \rightarrow \text { Knowledge } \\
\text { Transfer }\end{array}$ & 0.20 & 4.29 & 0.00 & Accept*** \\
\hline $\mathrm{H} 2$ & Trust $\rightarrow$ Knowledge Transfer & 0.22 & 4.91 & 0.00 & Accept $* * *$ \\
\hline $\mathrm{H} 3$ & $\begin{array}{l}\text { Soft Reward } \rightarrow \text { Knowledge } \\
\text { Transfer }\end{array}$ & 0.13 & 2.68 & 0.01 & Accept** \\
\hline $\mathrm{H} 4$ & $\begin{array}{l}\text { Personality } \rightarrow \text { Knowledge } \\
\text { Transfer }\end{array}$ & 0.31 & 5.76 & 0.00 & Accept*** \\
\hline H5 & $\begin{array}{l}\text { Knowledge Transfer } \rightarrow \\
\text { Knowledge Performance }\end{array}$ & 0.61 & 17.36 & 0.00 & Accept*** \\
\hline
\end{tabular}

\section{DISCUSSION}

The research results also confirm the positive direct effects of trust, helping others, soft rewards and personality for knowledge transfer behaviour. We found that knowledge transfer behaviour influence to knowledge transfer performance. We measures that knowledge transfer behaviour from two sub-factors that donation and collecting knowledge among employees based on [31], [50]. Then, for knowledge transfer performance was examined by the scale adapted from [29], [30], these items measured by easy to understand, accuracy, completeness, reliability, and timeliness. 
Many previous studies also suggested that helping others among employees is one of the success factors of knowledge transfer behaviours. The results of this study showed that helping others $(\mathrm{H} 1$, coefficient $=0.20, \mathrm{p}<0.05)$, have significant influence on knowledge transfer behaviours. Helping others as including discretionary behaviours that help specific others with organizationally relevant tasks or problems Organ (1998) as cited in [10].

Trust among employees is a critical factor that influences knowledge transfer behaviour [35][39]. The results of this study showed that trust $(H 2$, coefficient $=0.22, p<0.05)$, have significant influence on knowledge transfer behaviours. The result also indicates that trust among the employees is considered as an important factor that influences employees to share knowledge. This suggests that employees may share their knowledge based on trust and irrespective of others different cultures, educational level and also job position.

The results of this study showed that soft reward a positive influence on knowledge transfer behaviour $(\mathrm{H} 3$, coefficient $=0.13, \mathrm{p}<0.05)$. Rewards are defined as individuals expectations of achieving implicit outcomes (e.g., personal reputation and relationships with significant others) in return for performing knowledge transfer behaviour [18], [41], [42].

Based on the PLS results, is that personality should implement a supportive knowledge transfer behaviours. The results of this study showed that personality $(\mathrm{H} 5$, coefficient $=0.31, \mathrm{p}<0.05)$, have significant influence on knowledge transfer behaviours and also personality is that have a higher number of path coefficient among all factors that influence to knowledge transfer behaviour.

In this research found is that knowledge transfer behaviour (coefficient $=0.61$ ), have significant influence on knowledge performance. Knowledge transfer has two facets, collecting or receiving and disseminating or sending knowledge.

\section{CONCLuSion}

This is important because it is still crucial to accurately explain the knowledge transfer behaviour of individual professional groups [3] and also because team and organizational level knowledge is influenced by the extent to which knowledge transfer occurs between employees [4]-[7]. For this reason, we have provided a research model derived from previous studies to be tested in a nonprofit organization. This would provide helpful guidelines for human resource managers and knowledge employees working in today's growing number of knowledge-intensive organizations. As mentioned earlier, this study attempted to fill the gap in the current literature by examining the factors that influence knowledge transfer among employees of non-profit organizations. The results of this study indicated that helping others, trust, soft reward, and personality have an influence on knowledge transfer, and also knowledge transfer behaviour have an influence on knowledge performance.

\section{REFERENCES}

[1] F. A. Uriarte, “Introduction to Knowledge Management,” Igarss 2014, no. 1, pp. 1-5, 2008.

[2] S. Alam, Z. Abdullah, N. Ishak, and Z. Zain, "Assessing Knowledge Sharing Behaviour among Employees in SMEs: An Empirical Study,” Bus. Res., no. 1998, pp. 115-122, 2009.

[3] S. Ryu, S. H. Ho, and I. Han, "Knowledge sharing behavior of physicians in hospitals," Expert Syst. Appl., vol. 25, no. 1, pp. 113-122, 2003. 
[4] E. F. Cabrera and A. Cabrera, "Fostering knowledge sharing through people management practices," Int. J. Hum. Resour. Manag., vol. 16, no. May, pp. 720-735, 2005.

[5] I. Nonaka, "A Dynamic Theory of Organizational Knowledge Creation," Organization Science, vol. 5, no. 1. pp. 14-37, 1994.

[6] P. Fingesten, "The tacit dimension ?: Garden City, N.Y., Doubleday and Co., 1966, 108 pages," J. Commun. Disord., vol. 1, no. 4, pp. 346-347, 1968.

[7] H. Tsoukas and E. Vladimirou, "What is organizational knowledge?," J. Manag. Stud., vol. 38, no. 7, pp. 972-993, 2001.

[8] T. H. Davenport, “Ten principles of knowledge management and four case studies,” Knowl. Process Manag., vol. 4, no. 3, pp. 187-208, 1997.

[9] S. Gao, "Understanding knowledge sharing behavior." pp. 1-87, 2004.

[10] H. F. Lin, "Effects of extrinsic and intrinsic motivation on employee knowledge sharing intentions," J. Inf. Sci., vol. 33, no. 2, pp. 135-149, 2007.

[11] S. Moffett, R. McAdam, and S. Parkinson, "An empirical analysis of knowledge management applications,” J. Knowl. Manag., vol. 7, no. 3, pp. 6-26, 2003.

[12] H. Lee and B. Choi, "Knowledge management enablers, processes, and organizational performance : An integration and empirical examination,” J. Manag. Inf. Syst., vol. 20, no. 1, pp. 179-228, 2003.

[13] M. C. Jones, M. Cline, and S. Ryan, "Exploring knowledge sharing in ERP implementation: An organizational culture framework," Decis. Support Syst., vol. 41, no. 2, pp. 411-434, 2006.

[14] G. Bock, R. Zmud, and J.-N. Lee, "Behavioral Intention Formation in Knowledge Sharing," MIS Quarterly, vol. 29, no. 1. pp. 87-111, 2005.

[15] G.-W. Bock and Y.-G. Kim, "Breaking the Myths of Rewards: An Exploratory Study of Attitudes about Knowledge Sharing,” Inf. Resour. Manag. J., vol. 15, no. 2, pp. 14-21, 2002.

[16] G. W. Bock and Y.-G. Kim, "Breaking the Myths of Rewards,” Inf. Resour. Manag. J., vol. 15, no. 2, pp. 14-21, 2002.

[17] S. H. Kwok and S. Gao, “Attitude Towards Knowledge Sharing Behavior,” J. Comput. Inf. Syst., vol. 46, no. 2, pp. 45-51, 2005.

[18] A. Kankanhalli, B. C. Y. Tan, and K.-K. Wei, "C Ontributing K Nowledge To E Lectronic K Nowledge R Epositories : a N E Mpirical,” MIS Q., vol. 29, no. 1, pp. 113-143, 2005.

[19] H. Gumbley, “Knowledge Management,” Emerald Insight, vol. 47, no. 5, pp. 175-177, 1998.

[20] H. H. Chang and S.-S. Chuang, "Social capital and individual motivations on knowledge sharing: Participant involvement as a moderator,” Inf. Manag., vol. 48, no. 1, pp. 9-18, 2011.

[21] Saide and N. E. Rozanda, "Analisis kebutuhan manajemen pengetahuan pada perusahaan perbankan 1,” Open Access J. Inf. Syst., vol. 5, no. 3, pp. 343-351, 2015.

[22] Saide and E. Mahendrawathi, "Knowledge Management Support For Enterprise Resource Planning Implementation,” Procedia - Procedia Comput. Sci., vol. 72, pp. 613-621, 2015.

[23] F. A. Uriarte, "Introduction to knowledge management in the NHS," Asean Found., p. 179, 2008. 
[24] P. J. Hinds, M. Patterson, and J. Pfeffer, "Bothered by abstraction: the effect of expertise on knowledge transfer and subsequent novice performance.," J. Appl. Psychol., vol. 86, no. 6, pp. 12321243, 2001.

[25] F. Blackler, "Knowledge, Knowledge Work and Organizations: An Overview and Interpretation," vol. 16, no. 6. pp. 1020-1046, 1995.

[26] Y. H. Al-Qadhi, K. Md Nor, A. C. Ologbo, and M. B. Knight, "Knowledge sharing in a multinationality workforce: Examining the factors that influence knowledge sharing among employees of diverse nationalities,” Hum. Syst. Manag., vol. 34, no. 3, pp. 149-165, 2015.

[27] W. T. Wang and Y. P. Hou, "Motivations of employees' knowledge sharing behaviors: A selfdetermination perspective," Inf. Organ., vol. 25, no. 1, pp. 1-26, 2015.

[28] M. B. Ismail and Z. M. Yusof, "The Contribution of Technological Factors on Knowledge Sharing Quality among Government Officers in Malaysia,” Knowl. Manag., pp. 239-255, 2010.

[29] W. H. Delone and E. R. Mclean, "Information Systems Success: The Quest for the Dependent Variable," no. 4, 1992.

[30] W. Delone and E. McLean, "The DeLone and McLean model of information systems success: a tenyear update,” J. Manag. Inf. ..., vol. 19, no. 4, pp. 9-30, 2003.

[31] S. Mohammed, A. Syed, and A. Alhady, "Knowledge Sharing Behavior and Individual Factors : A Relationship study in the i-Class Environment," Ipedr, vol. 6, pp. 137-141, 2011.

[32] D. Constant, K. Sara, and S. Lee, "Whats Mine is Ours, or is it? A study of Attitudes about Information Sharing.” 1994.

[33] H. Lin, "Knowledge sharing and firm innovation capability: an empirical study," Int. J. Manpow., vol. 28, no. 3/4, pp. 315-332, 2007.

[34] M. M. Wasko and S. Faraj, "Why Should I Share? Examining Social Capital and Knowledge Contribution in," vol. 29, no. 1, pp. 35-57, 2005.

[35] C.-M. Chiu, M.-H. Hsu, and E. T. G. Wang, "Understanding knowledge sharing in virtual communities: An integration of social capital and social cognitive theories," Decis. Support Syst., vol. 42, no. 3, pp. 1872-1888, 2006.

[36] W. S. Chow and L. S. Chan, "Social network, social trust and shared goals in organizational knowledge sharing," Inf. Manag., vol. 45, no. 7, pp. 458-465, 2008.

[37] C.-L. Hsu and J. C.-C. Lin, “Acceptance of blog usage: The roles of technology acceptance, social influence and knowledge sharing motivation,” Inf. Manag., vol. 45, no. 1, pp. 65-74, 2008.

[38] W. He and K.-K. Wei, "What drives continued knowledge sharing? An investigation of knowledgecontribution and -seeking beliefs,” Decis. Support Syst., vol. 46, no. 4, pp. 826-838, 2009.

[39] B. van den Hooff and M. Huysman, "Managing knowledge sharing: Emergent and engineering approaches,” Inf. \&amp; Manag., vol. 46, no. 1, pp. 1-8, 2009.

[40] M. Sharrat and A. Usoro, "Understanding Knowledge Sharing in Online Communities of Practice," Electron. J. Knowl. Manag., vol. 1, no. 2, pp. 187-196, 2003.

[41] H. G. K. Hummel, D. Burgos, C. Tattersall, F. Brouns, H. Kurvers, and R. Koper, "Encouraging contributions in learning networks using incentive mechanisms," J. Comput. Assist. Learn., vol. 21, no. 5, pp. 355-365, 2005. 
[42] H. Hall and D. Graham, "Creation and recreation: motivating collaboration to generate knowledge capital in online communities,” Int. J. Inf. Manage., vol. 24, no. 3, pp. 235-246, 2004.

[43] M. Gagne, "Hrm: Implications for the Professionals," Hum. Resour. Manage., vol. 45, no. 3, pp. 295-308, 2009.

[44] M. Gagne and E. L. Deci, "Self-determination theory and work motiviation," J. Organ. Behav., vol. 26, no. October 2003, pp. 331-362, 2005.

[45] P. van den Brink, Social, Organizational and Technological Conditions that enable Knowledge Sharing. 2003.

[46] B. Van Den Hooff and J. A. De Ridder, "Knowledge sharing in context: The influence of organizational commitment, communication climate and CMC use on knowledge sharing Knowledge sharing in context: the influence of organizational commitment, communication climate and CMC use on knowledge" 2004.

[47] J. Darroch, R. Mcnaughton, J. Darroch, and R. Mcnaughton, "Examining the link between knowledge management practices and types of innovation," 2006.

[48] M. E. Jennex and L. Olfman, "Assessing Knowledge Management Success / Effectiveness Models," vol. 00, no. C, pp. 1-10, 2004.

[49] R. Cheung and D. Vogel, "Predicting user acceptance of collaborative technologies: An extension of the technology acceptance model for e-learning," Comput. Educ., vol. 63, pp. 160-175, 2013.

[50] J. P. Nicolai, D. B. Minbaeva, T. Pedersen, and M. Reinholt, "Encouraging Knowledge Sharing Among Employees: How Job Design Matters,” Hum. Resour. Manage., vol. 45, no. 3, pp. 295-308, 2009.

[51] Y. H. Al-Qadhi, K. Md Nor, A. C. Ologbo, and M. B. Knight, "Knowledge sharing in a multinationality workforce: Examining the factors that influence knowledge sharing among employees of diverse nationalities,” Hum. Syst. Manag., vol. 34, no. 3, pp. 149-165, 2015.

[52] W.-T. Wang and Y.-P. Hou, "Motivations of employees' knowledge sharing behaviors: A selfdetermination perspective,” Inf. Organ., vol. 25, no. 1, pp. 1-26, 2015.

[53] A. Sarkheyli, R. A. Alias, N. Ithnin, and M. D. Esfahani, "Dimensions of Knowledge Sharing Quality: An Empirical Investigation,” J. Res. Innov. Inf. Syst., pp. 9-18, 2013.

[54] C. M. Chiu and E. T. G. Wang, "Understanding Web-based learning continuance intention: The role of subjective task value,” Inf. Manag., vol. 45, no. 3, pp. 194-201, 2008.

[55] J. F. Hair, C. M. Ringle, and M. Sarstedt, "PLS-SEM: Indeed a Silver Bullet,” J. Mark. Theory Pract., vol. 19, no. 2, pp. 139-152, 2011.

[56] J. F. Hair, M. Sarstedt, C. M. Ringle, and J. A. Mena, "An assessment of the use of partial least squares structural equation modeling in marketing research," pp. 414-433, 2012.

[57] J. Hulland, "Use of partial least squares (PLS) in strategic management research: A review of four recent studies," Strateg. Manag. J., vol. 20, no. 2, pp. 195-204, 1999.

[58] C. Fornell, D. F. Larcker, and S. Modeling, "Equation Algebra Error :," vol. XVIII, no. August, pp. 382-388, 1981.

[59] W. W. Chin, "The partial least squares approach to structural equation modeling," Mod. methods Bus. Res., pp. 237-246, 1998. 
[60] D. Gefen, "Structural Equation Modeling and Regression : Guidelines for Research Practice Structural Equation Modeling and Regression: Guidelines for Research Practice," Struct. Equ. Model., vol. 4, no. August, p. 7, 2000.

\section{AUTHORS}

Saide.

He is currently Double Degree Master Student which in Department of Information Management at National Taiwan University of Science and Technology and Department of Information Systems at Institute Technology of Sepuluh Nopember (ITS), Surabaya, Indonesia. Received the B.Sc. degree of information systems in 2013 at State Islamic University of Sultan Syarif Kasim Riau, Indonesia.

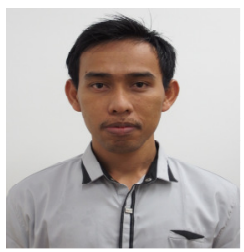

His research majors includes knowledge management strategy, knowledge transfer framework, management information system, renewable energy, and project management. He also executive of operational management and project management at energy research center (enreach.or.id), Riau, Indonesia.

\section{Dr. Hsiao-Lan Wei.}

She is an associate professor at Department of Information Management, National Taiwan University of Science and Technology, Taiwan. She did her B.Sc degree in National Tsing Hua University. She received her M.Sc (1995) and Ph.D (2006) degree at National Central University, Taiwan.

Her research fields are in supply chain management, enterprise resource management, production management, and cross-organization information management.

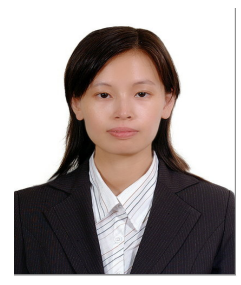

\section{Dr. Apol Pribadi Subriadi.}

Currently he is chairman of graduate study and lecturer at Department of Information System at Institute Technology of Sepuluh Nopember (ITS), Surabaya, Indonesia. She did her B.Sc degree in Department of Electrical Engineering (1994) at ITS Surabaya University, M.Sc in Department of Industrial Engineering (2000) at ITS Surabaya University, and Ph.D degree at Department of Management and Business of Brawijaya University (2013).

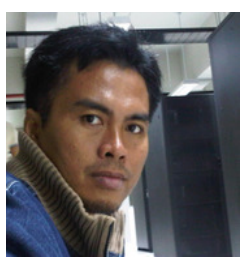

His research interests includes information systems (business informatics), management information systems, information system management, online research methods, IT/IS investment, and IT/IS- bussiness alignment.

\section{Dr. Okfalisa}

Okfalisa finished her $\mathrm{PhD}$ in information System and Computer Science at Universiti Teknologi Malaysia in 2012. Her research focuses on performance measurement, strategy execution, management information system and decision support system through several research project, national and international publications funding by University Islamic Suska Riau and Indonesia Islamic Higher Education Ministry. She also reviews some locals and international journals under Scopus. Currently she is senior lecturer in Informatics Engineering Department and serves as vice dean of students' affairs and collaboration in Science and Technology Faculty University

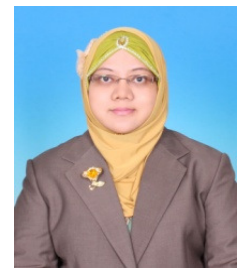
Islamic Suska Riau Indonesia. 


\section{Nurul Aini}

She is currently Master Degree Student of Information System Department at Diponegoro University, Semarang, Indonesia. She did her B.Sc degree of Information System in 2012 at State Islamic University of Sultan Syarif Kasim Riau, Indonesia.

His research fields includes Green ICT, Management Information System, and Supply Chain Management.

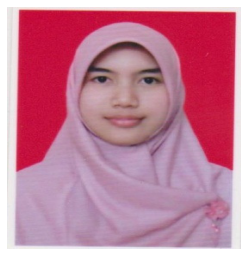

\section{Nesdi Evrilyan Rozanda, M.Sc}

Currently he is chair of board of Energy Research Center (enreach.or.id) and lecturer at Department of Information System, State Islamic University of Sultan Syarif Kasim Riau, Indonesia. She did her B.Sc degree in Computer Science of STMIK "YPTK" Padang, West Sumatera Indonesia, and M.Sc titled in Universiti Teknologi Malaysia.

His research interests includes information systems, green ICT, knowledge

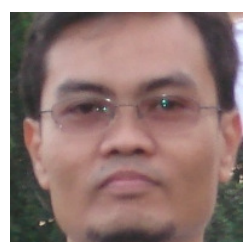
management, renewable energy and artificial intelligence. 